\title{
Wellbeing and Smart Textiles: Reflecting on Collaborative Practices and the Design Process
}

Dr Amanda Briggs-Goode, Dr Martha Glazzard, Sarah Walker, Dr Sarah Kettley, Dr Tincuta Heinzel, Rachel Lucas

College of the Architecture, Art, Design and the Built Environment Nottingham Trent University

Burton Street

Nottingham

NG1 4BU

$+44(0) 1159418418$

Amanda Briggs-Goode is head of department of fashion, textiles, knitwear at Nottingham Trent University and is co-investigator on the EPSRC Internet of Soft Things project. She has authored Printed Textile Design with Laurence King and co-edited Lace:here:now with Black Dog publishing and Textile Design with Woodhead Publishing.

amanda.briggs-goode@ntu.ac.uk

Martha Glazzard is a Research Fellow on the EPSRC An Internet of Soft Things project and Lecturer at Nottingham Trent University and completed her PhD in 2014 'Re-Addressing the Role of Knitted Textile Design Knowledge: Auxetic Textiles From a Practice Led, Designer Maker Perspective' martha.glazzard@ntu.ac.uk

Sarah Walker is a PhD student at Nottingham Trent University and holds a Vice Chancellors Bursary. Sarah works with smart textiles and participatory design.

sarah.walker2012@ntu.ac.uk

Sarah Kettley is the Principal Investigator on the EPSRC An Internet of Soft Things project and is a Reader in Relational Design at Nottingham Trent University. Sarah has published extensively with her first book being launched in July 2016 'Designing with Smart Textiles' with Bloomsbury.

sarah.kettley@ntu.ac.uk

Tincuta Heinzel is a Research Fellow on the EPSRC An Internet of Soft Things project. Tincuta completed her PhD in 2012 and has published extensively in the field of electronic textiles. 
tincuta.heinzel@ntu.ac.uk

rachel.lucas@ntu.ac.uk

Rachel Lucas is a Research Fellow on the EPSRC An Internet of Soft Things project and after having trained as a textile designer made a career change into person centred psychotherapy which she now practices.

\section{Acknowledgements:}

The work was supported by a Research-In-The-Wild grant from the EPSRC (EP/L023601/1) and was also supported by the Nottinghamshire Mind Network. The authors wish to thank the members of Bassetlaw Mind, UK for their enthusiasm and engagement with the project.

\section{Abstract}

This paper reports on an inter-disciplinary, EPSRC funded research project, 'An Internet of Soft Things' (IoSofT) which seeks to bring soft surfaces, smart textiles and wearable technologies to join the Internet of Things debate. The project involves researchers from academic disciplines: design, computing and mental health in collaboration with a project partner, the Nottinghamshire network of the mental health charity, Mind. This paper will reflect upon the research project and specifically the approach the authors have taken to collaborative textile practice and how this has impacted upon the design process. This project was conducted through a number of practical workshop activities with Mind service user groups. The workshops focused upon the crafting of personalized textile objects with soft switches and various output and also recorded the clients' descriptions of their sense of ownership, awareness of their own and others' emotions and behaviours. The workshops included the researchers' reflections and observations to enable further understanding of how this community invests meaning in material things and modes of expressive output. The aim of the research project is to use textile craft practice and smart materials alongside therapeutic approaches to contribute to the development of a wellbeing and mental health toolkit to support future client work for Mind.

Keywords: wellbeing, mental health, loSofT, smart textiles, wearable technologies 


\section{The project}

The project 'An Internet of Soft Things' (IoSofT), based at Nottingham Trent University was funded by the EPSRC and brought together a unique combination of person centred psychotherapists, textile designers and computer scientists (An Internet of Soft Things 2016a). Its aim was to develop a co-design methodology through practice-led critical reflection on the Person Centred Approach (PCA) in order to benefit non-medicalized care practices using craft, electronic textiles and interactive computing, to develop networked textile objects. The use of the PCA was a vital part of the project to ensure participants understood that they were valued and appreciated for their contribution to the project through participation in workshops and the creative process (Rogers 1957). Craft practice was an important part of the approach as it offered numerous opportunities to develop understanding, confidence, relationships and trust. Although the approach was not explicitly art therapy, the team found that what was experienced as creative, was in most cases also experienced as therapeutic (Rogers 1993). Burt and Atkinson (2012: 56)in their study on the impact of craft on wellbeing (specifically quilting) noted that

"the majority of participants reported that the creative process captivated them, distracted them and they described an experience analogous to 'flow'. There was loss of selfconsciousness and lack of awareness of things going on around them, which displaced anxieties and facilitated relaxation."

During our workshops, the Mind staff who had established relationships with the participants made similar comparisons, noting how much longer people were able to concentrate and increased levels of engagement with the making-based activities. Yair (2011: 4) also notes that

"distraction, mood enhancement and relaxation has other benefits for well-being, quietening chronic stress and anxiety...and at the same time, both a sense of achievement gained from craft and the social interaction it encourages can help combat the isolation of depression."

The theoretical framework for the project asks how design can engage with the PCA to inform a new methodology for design and making. The PCA originated with Carl Rogers' theory and practice, and informs contemporary psychotherapy practice, nursing, pedagogy and conciliation approaches (Embleton-Tudor et al. 2004). One of the key drivers of this theory is that those participating should be able to do so within a non-judgemental environment or with unconditional positive regard (UPR) (Rogers 1957). The PCA is therefore both non-directive and non-judgemental (Levitt 2005) and takes a holistic view of experiencing, in contrast to the deficit model of medical approaches to mental 
health and wellbeing (including behavioural and clinical psychology). The medical model tends to act on clusters of symptoms (pathology) rather than viewing the whole person, while the behavioural approach is directive in nature, seeking to change individuals' behaviour to fit a societal norm. However, the PCA emphasises the person's movement towards growth, shown by open, flexible responses in the here-and-now (Rogers 1961). In the loSofT project the research is not concerned with participants' medical diagnoses, rather, we (as humans as well as researchers) strive to value the whole person. Workshops are framed as collaborative research, not therapy, and we aspire to provide co-researchers (not 'clients' or 'patients') with a framework to support their own journey of therapeutic change.

If co-design methodologies are primarily used to improve the design of objects and products, our focus was to use co-design as a way to help build designers-facilitated practice in relation to well-being. In this sense our approach was to use co-design as a method to develop a craft-practice service. The purpose of this service is double layered, as it aims to facilitate the making of electronic textiles and also allows for better understanding of the technical complexity of electronic textiles for potential users. As a service offered by a design or craft person, it is not to be confounded with art therapy, which is a mental health practice (Jaatinen 2015).

Thus the research enables people with lived experience of mental health issues, to participate in workshops, using a co-design methodology to create personalised textile objects. The involvement of therapeutic communities is central to the research process and this includes co-researchers from the Nottinghamshire Mind Network, working with service users with existing mental health needs. To enable us to create a person-centred working environment and co-design methodology, some common framing activities were borrowed from psychotherapeutic practice, such as the creation of a group agreement and the use of 'check-ins' and 'check-outs' at the beginning and end of each session; dialogical evaluation tools were also developed, including one based on the Recovery Star (Mackeith et al. 2013). These tools encouraged openness and reflexivity and gave each participant diverse opportunities to describe their experience of participation and their hopes and fears for the next session. It also gave the co-researchers feedback on skills levels for dynamic planning and timings, as well as enabling reflection on the experience of the time spent making within the group context.

The project lasted two years and was structured in three phases: 1) e-textile workshops, 2) Service Design workshops, and 3) Future Workshops for mental health service redesign. This was intended to scaffold participant experience with textile and electronic technologies, posit the concept of being able to design with data to support mental wellbeing, and finally visualise how a futuristic venue, 
enabled by a 'smart' system of networked personal textile artefacts and interior fittings, might enable new models of mental health and social care integration. This paper focuses on the experiences of the team throughout phases 1) and 2), as they sought to facilitate engagement with e-textile craft processes, and to create meaningful networked textile objects for data collection.

The key driver for the project, and the rationale for taking e-textiles to mental health service users, was the recognition that ubiquitous embedded technologies are increasingly being adopted in the health sector according to cognitive-behavioural models of the person and 'need', when other approaches may also be valuable (Tyrer and Steinberg 2013, Kettley et al. forthcoming). This research responded to a call from the Internet of Things development community for ways to put people at the heart of the design process, rather than technology (Innovate UK Network 2013). Furthermore, the project stresses the difference between designing with special needs and mental health participants. Very often in design, these communities are mentioned in the same breath, but mental health happens to us all, and very often has no impact on cognitive ability or intelligence. As an example, the Mind members who took part in this project included an employed anthropologist, a retired engineer, someone with years of experience working with a textile manufacturing company, another who had worked in the telecommunications manufacturing industry, and a retired bed and breakfast (B\&B) owner with strong ideas on interior decoration. Conversely, managers in the health sector are often proud to own their 'lived experience', and some members of the academic team could also count themselves in this category. Some of the research team had decades of experience working with people with complex special needs (Brown et al. 2011, Wallis and Jones 2013), but this project was a completely new experience for them.

\section{Methods used in collaboration}

\section{Methods used in workshops}

The workshops, which were first piloted in central Nottingham and then continued with Mind members and volunteers in North Nottinghamshire, employed similar strategies for collaborative working and co-design. Simple methods were prioritised and presented information in small, manageable chunks. The aim was to create an environment for creative and educational activities that facilitates both craft practice and electronic understanding, without losing sight of the well-being of participants in the moment. Making tasks with Mind members were often undertaken in pairs, with a member of the facilitation team. This pairing enabled facilitators to assist as much or as little as necessary, and in some cases to carry out physical acts of sewing on behalf of the 
participant, when aspects such as aggravated physical or mental health conditions made concentration or co-ordination difficult.

As part of the one-to-one assistance, the workshop facilitators, several of whom came from design backgrounds, were able to assist the participants in the design decision-making process. For example, by asking questions regarding switch selection and fabric colour choice. By breaking up the design process into discrete decisions with binary answers, the prospect of 'designing' became less daunting (one of the comments added to the pilot group agreement by a member of the academic team was that it should be 'OK not to be creative'). This enabled the significant aesthetic and functional aspects of each textile object to be determined by the participants. The workshops offered the possibility for direct observation in situ conditions of the designed set-up and framework. A series of sound and video recordings were also taken and they are about to be analyzed in a post-experience research phase.

\section{Methods used within the research team}

In addition to the wider scope of the project, several larger electronic textile objects were made by the researchers on the team. These prototypes explored the use of electronic textile objects by people with mental health issues and were used to illustrate different concepts, such as inputs and outputs in physical computing. Since electronic textiles demand diverse competencies, belonging to different disciplines, we have sought ways to support the different members of the research team to work collaboratively and to create smart textile objects. The team involved in developing the electronic textiles discussed below consisted of textile designers, a pattern cutting expert, an electronic textile designer and a computer science expert.

The design team adopted several methods to tackle the designing and making of the smart textile networked objects, similar to that of Gray and Malins (2004: 31) 'triangulation of methods', proposed for undertaking art and design research. Each design team member brought forward personal and taught methods from their disciplinary fields to assist in design development and team communication. Basic aspects like textile forms and materials, circuit design, interaction forms, programming, Internet of Things and Big Data were investigated. In addition to the first pilot workshops in central Nottingham, the electronic textiles designer and the computer scientist also provided the textile designers and psychotherapists on the team with workshop training in Arduino and programming. 
One of the most useful methods for visualising the circuits (designed by the computer science expert) was the use of the program Fritzing (2016). This allowed for realistic, diagrammatic representations of the circuits, which could be used as tools for discussion and adaptation. From a designer's perspective, the Fritzing tool was very valuable in generating tangible visuals, but it was limited in reflecting how the real-world textile outcome would look, due to the use of straight lines and schematic, idealised visual representations. Another problem occured due to the nature of the program, which crosses, merges and overlays wires in ways that conductive thread cannot, without causing a short circuit. For example, Figure 1 shows the wire crossing the Photon board (Particle 2016), which would not be possible with threads. When making the electronic textiles practically, the Fritzing diagram acted as a reference point from which the elements could be moved around to better reflect the final stitched circuit. Where this was not possible, the salient information was used to recreate the circuit on the textile e.g. that the $Y$ from the accelerometer is connected to Analogue pin 3 (as in Figure 1).

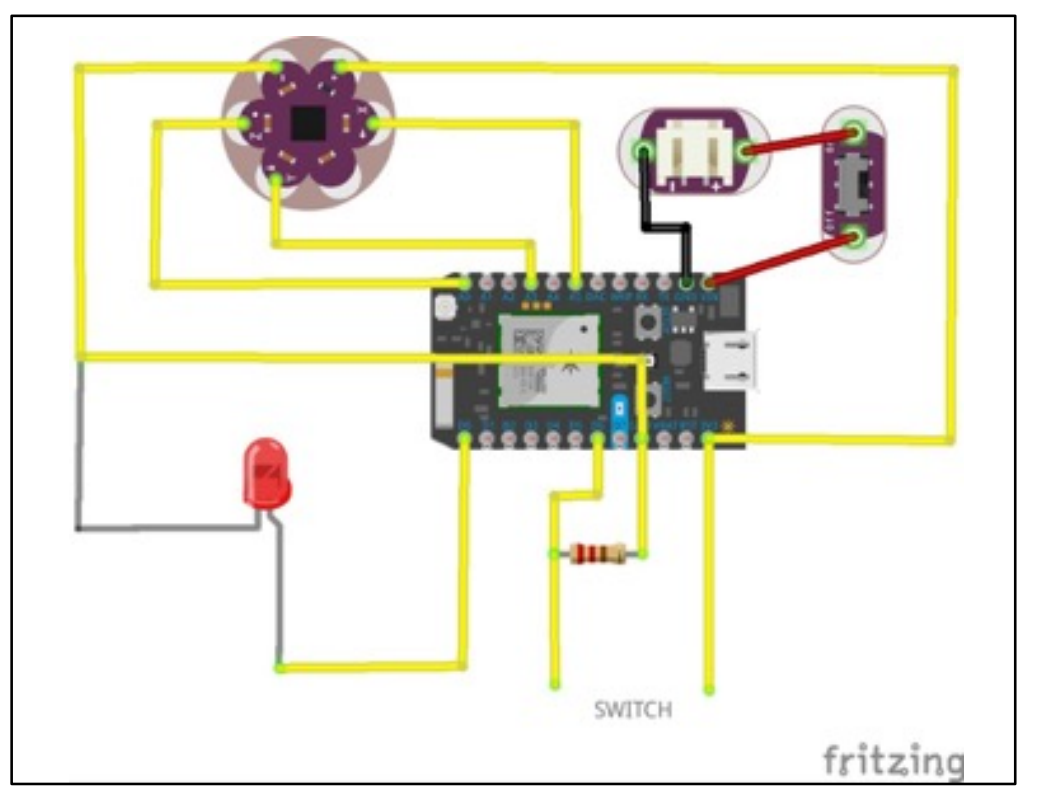

Figure 1. Fritzing diagram showing schematic for handheld electronic textile object.

In addition to the use of Fritzing, rough paper sketches and photographs were used to develop the electronic textiles and communicate the details between collaborators. By using a combination of specialist and these more readily accessible, low-tech methods, collaborators were able to develop mutual understanding. Each collaborator remained the expert in their respective field, but was expected to be aware of enough of their fellow collaborators' areas in order to communicate successfully. Communication was kept jargon-free and accessible to all wherever possible. 


\section{Participant-led textile objects}

During the two sets of Mind workshops, participants were supported to make their own electronic textile objects. The outline of each object-making activity was designed as a simple introduction to the field of electronic textiles, which would be achievable in an afternoon session and without the need for any computer programming. For further details on the content of the workshops see Glazzard et al. (2015: 4) and Briggs-Goode et al. (2015).

The workshop activities were divided as follows (see Figure 2 for examples) and those considered to be participant-led textile objects were created in Activities 3, 4 and 5.

Activity 1. Simple textile circuit

Activity 2 . Simple circuit with press stud switch (2 variations)

Activity 3. Garments such as gloves, socks, hats, etc. with circuits added

Activity 4. A group circuit, which is a small object with an individual circuit, which can be attached to other objects to make a larger circuit

Activity 5. A self-directed textile object using the skills from the previous activities
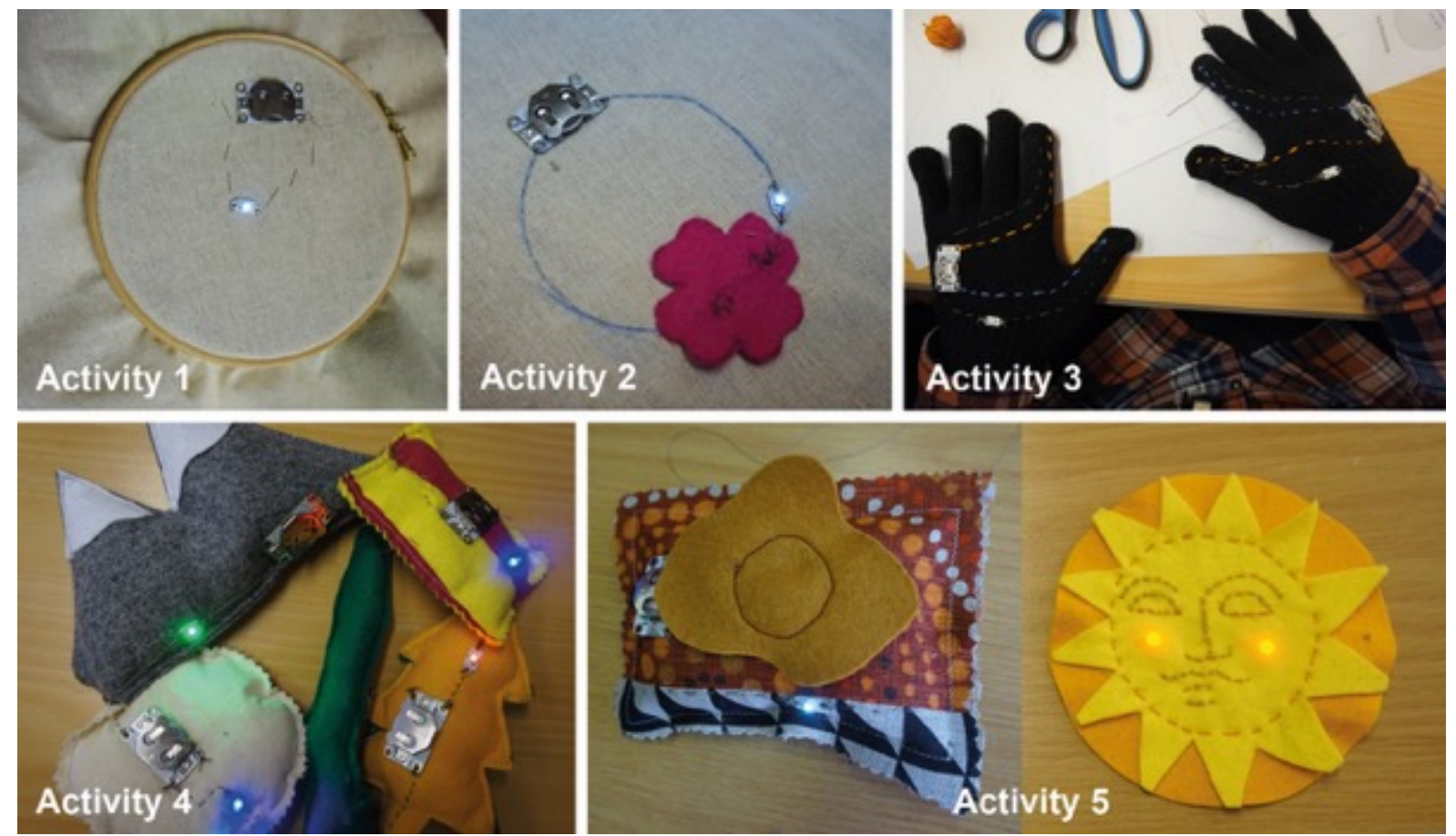

Figure 2. Images of the outcomes of the five making activities with the Mind participant group.

Participants made their own decisions on shape, colour, design and functions used in the making of the objects, during the workshops. Although these electronic textile objects were simple in their construction and function, the participants were engaging with largely unfamiliar processes and 
synthesising these outcomes with their own interests from their personal experiences. All objects used light emitting diodes (LEDs) as output, as this is a relatively simple circuit to achieve; the qualities and uses of lights for communication were discussed early on in the six-week process to help people think through design ideas. Participants were able to make both in-series and in-parallel circuits; the first of these is limited in the number of LEDs that can be powered, while a circuit arranged in parallel can power a larger number of lights from a single battery. Parallel circuits were used by some participants to make wristbands with multiple lights. The objects shown in Figure 2: Activity 5 were completely self-directed objects developed from the previous activities. The image shows a representation of 'ravioli and brown sauce', which was designed around the action of a magnetic switch from Kitronik. The 'brown sauce' contains a small magnet, which completes the circuit to activate an LED when attached to the 'ravioli'. The sun image shows an object with personal connections to a participant's spiritual beliefs. The sun object had a simple on/off switch controlling two LEDs in the 'cheeks' and was largely made by a workshop facilitator under instruction from the participant.

\section{Designer-led textile objects}

After the initial workshop stages (phase 1), the research team developed electronic textile objects inspired and informed by their experiences. These objects are split into two areas, hand-held and larger (physical) scales. These textile objects have one sensing form (capacitive, push button, etc.) rather than multiple forms of sensing (multimodal) so that the role of physical inputs and outputs, and design with data, could be made explicit.

The hand-held objects' initial functions were determined in part by the data collection approach within the project, and were used as props to prompt discussion about what data should be shared, with whom, and what experiences of that might be like. The objects were designed to capture data in response to walks 'in the wild' with Mind participants, while they shared their experiences during conversations with the researchers about environmental triggers, moment-to-moment observations and how those could be communicated through or to the objects. The larger-scale objects were designed to act as demonstrators of the possibilities of e-textiles in home-like environments. These were used in workshops with Mind service users and other groups for discussion on usage and interaction, as well as the future possibilities for the connectivity of textile objects.

\section{Hand-held objects}

\section{Various unsuccessful hand-held objects}


The project team designed and made several variations of soft tactile objects to be networked but found that when it came to applying electronic components, compatibility became an issue. For example, a hand-felting process was used to develop a series of three-dimensional soft objects. Although the soft texture of the object was easy to add additional features to by stitching, it was not easy to apply all of the hard electronic components needed to make the circuit. This was due to the object being integrally three-dimensional, meaning that it could not be taken apart in order to add the circuit, as well as the surface area being too small to add complex circuits. Therefore, this issue led to the handmade felt object being abandoned.

Another set of objects that were discarded as part of the learning-through-making process included a soft wristband and a small hand held cushion. Each item was constructed using materials that were feasible for the electronic circuit to be applied, however when it came to being used within the workshops for data collection with participants, the objects failed to work. As a result, parts of the circuit were dismantled and re-used for other developing ideas. A continuing challenge for the project members was realising that once the circuit was applied using e-textile materials the circuit might no longer work, despite being functional in principle. Such issues that led the object to not being functional included the strength and conductivity of the e-textile thread (discussed later in this paper).

Part of the challenge of the making was down to the large number of research team members. Successful outcomes most often came from pairs or individuals, with other team members needed for feedback or specific expertise, rather than all giving equally-weighted input. In some cases, prioritizing a mainly therapeutic or textile design perspective did not allow for time to discuss aspects related to interactivity with electronic textiles, or the use of data generated by different textiles devices.

\section{LED and accelerometer object}

The object that was primarily used to capture data during the second phase of Mind workshops was a small cushion, created using copper wiring to connect the components and board, simply contained within a small, padded, fabric cushion. This object was made by one of the researchers with computer science expertise to the specifications required for the data capture. The object had no particular aesthetic consideration and had the appearance of a plain black, square cushion with the LED and accelerometer stitched to the outside. Later a cover was made by one of 
the textile practitioners for the cushion to give a neater appearance. This cover incorporated a reverse applique hole filled with organza to allow the LED to shine through.

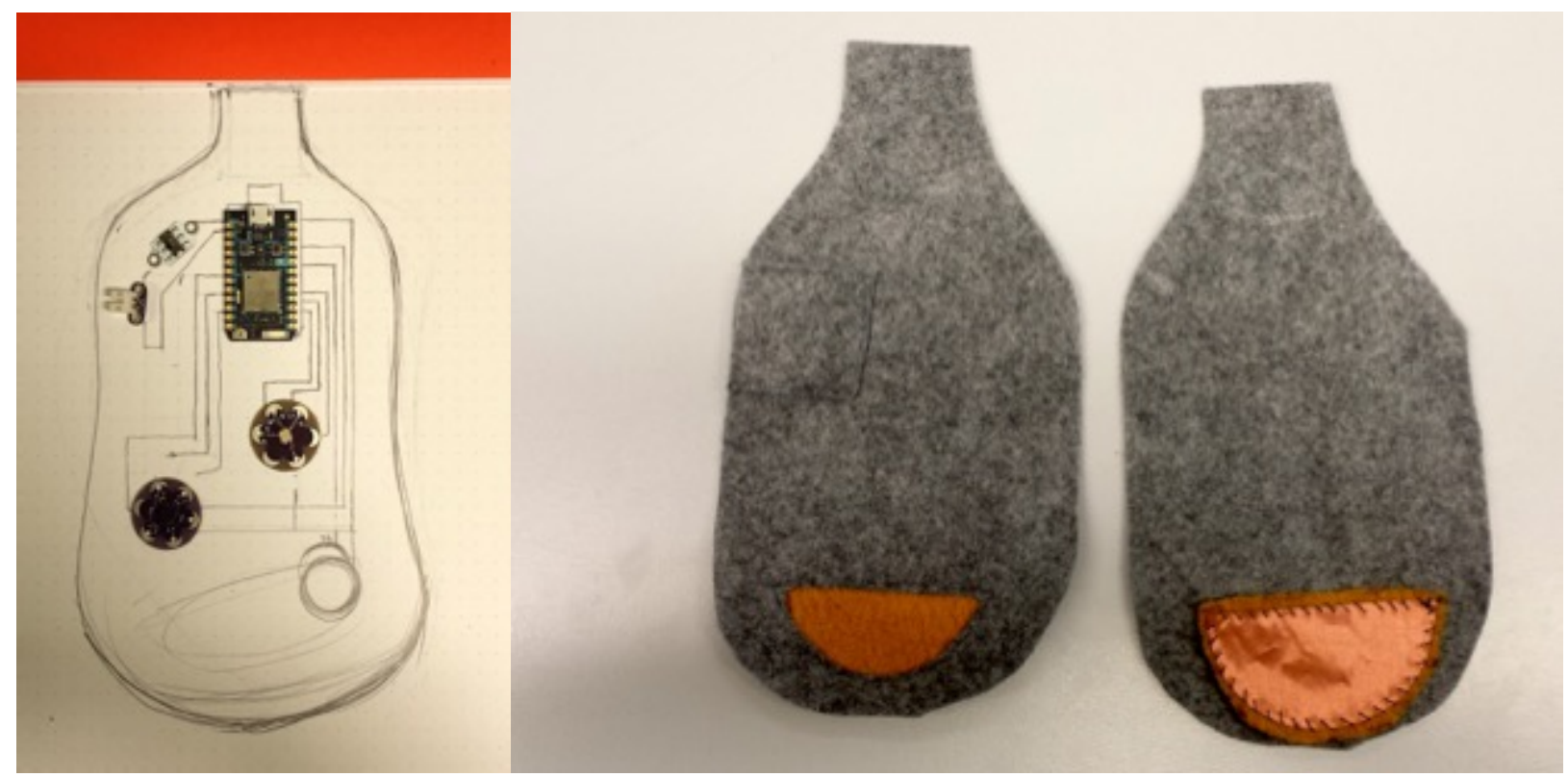

Figure 3. Images of one of the hand-held objects using an accelerometer, on/off switch, push button and a three colour LEDs Lilypad board with a Photon board for wireless communication. Preparatory circuit sketch and intermediary object.

\section{Larger scale objects}

\section{Capacitive ball rug}

The development of the capacitive ball rug came from the need to design larger-scale textile objects as part of the project. The brief for the project team was very open, but a recent workshop with some participants had shown that they had enjoyed interacting with round shapes. Martha Glazzard, who developed the ball rug, used her background in knitted textiles to work with jersey fabric in the aim of creating a soft, stretchy textile piece that could be touched and squashed to create electronic interactions. The ball rug is split into five 'zones' (distinguishable by different colours of fabric) each of which has a capacitive area consisting of six connected pieces of appliqued conductive fabric. Made flat in a patchwork style (as shown in Figure 4), the rug was then handmanipulated to transform the flat surface into a dense, three-dimensional rug of wadding-stuffed 'balls' (shown in Figure 5). The five capacitive areas can be activated by light skin contact as well as by more vigorous handling so the user's interactions can be suitable to their particular interaction preferences. 


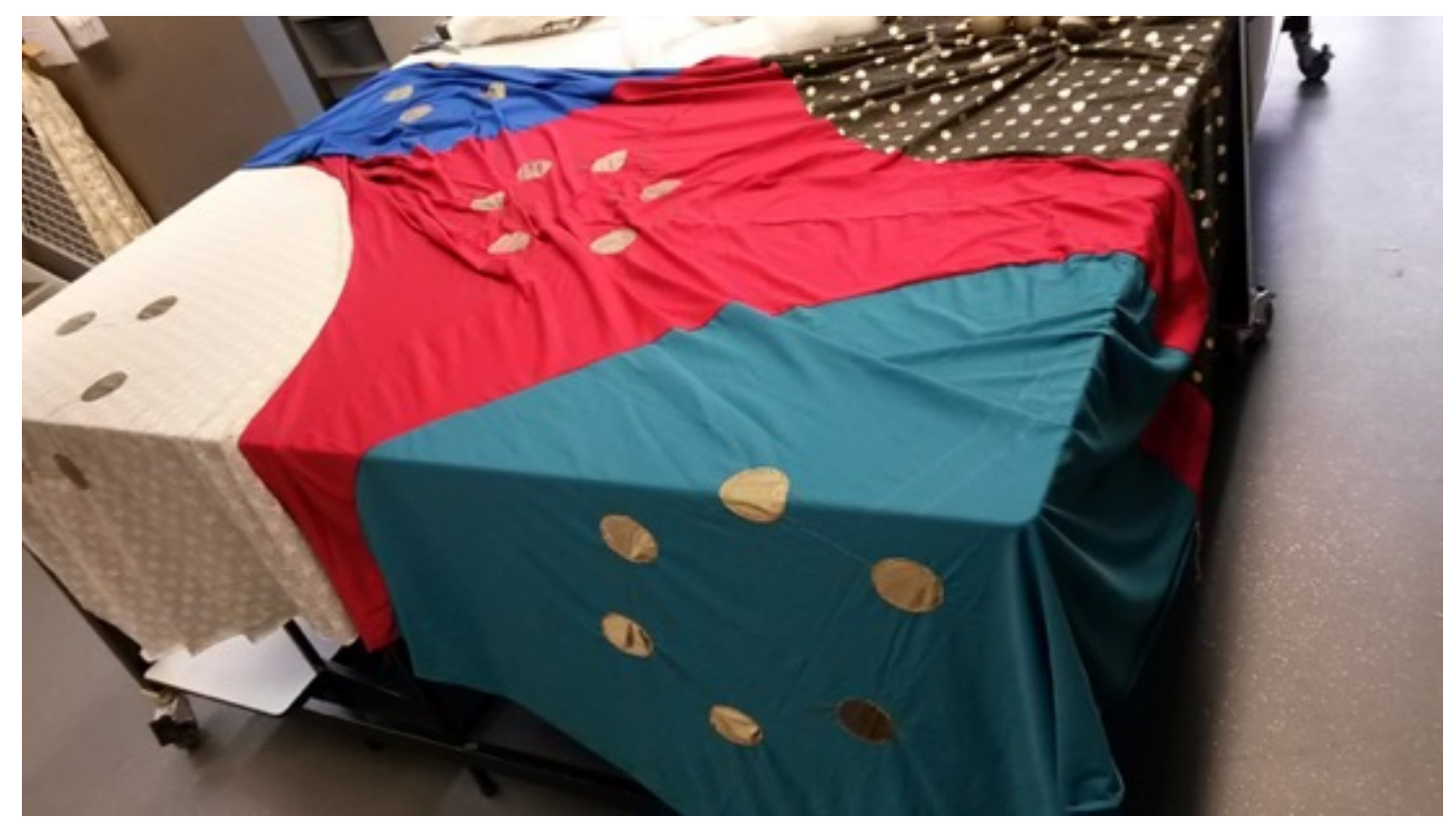

Figure 4. Capacitive ball rug in development, showing the five panels pieces together with the appliqued conductive fabric.

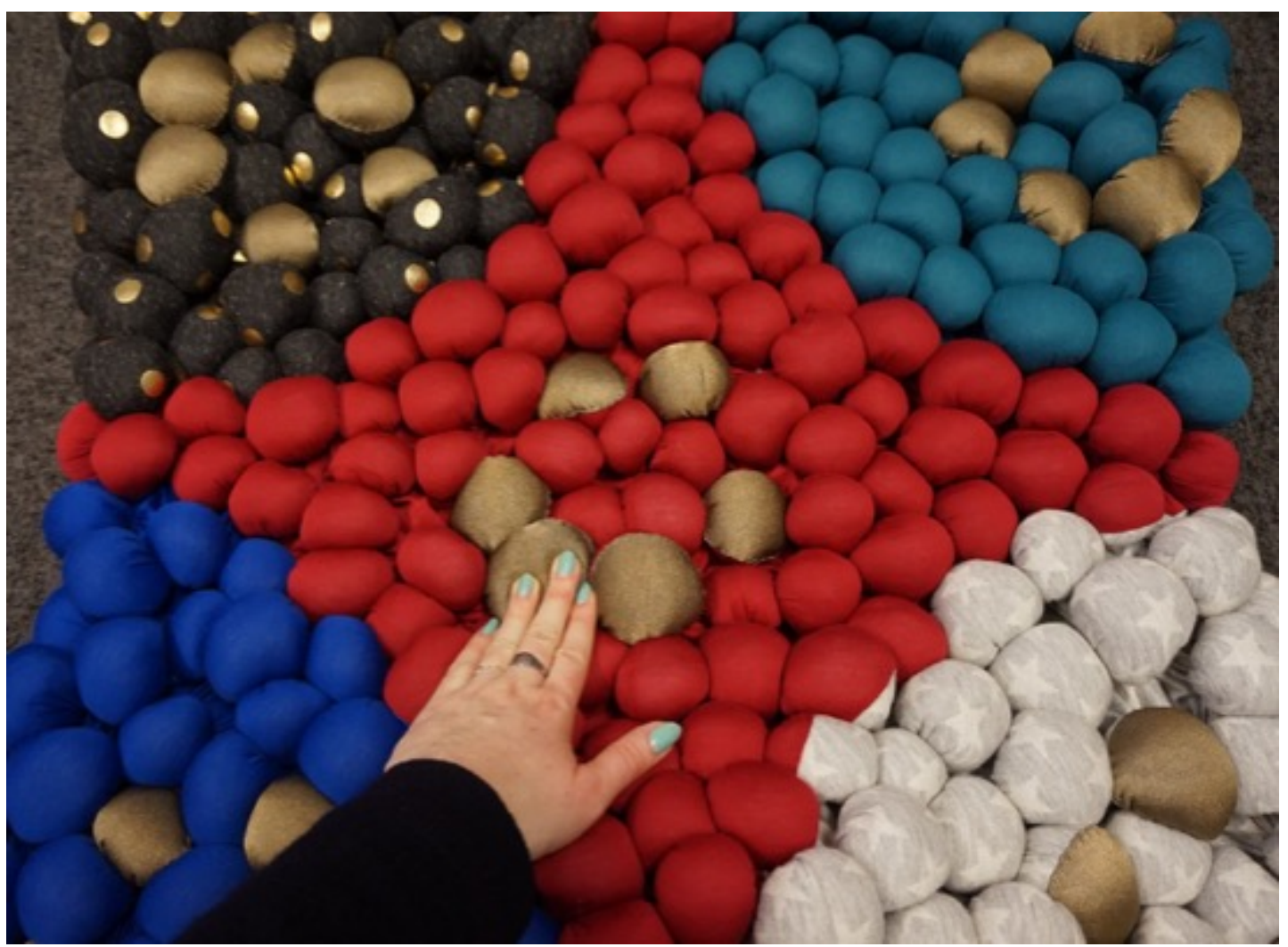

Figure 5. Capacitive ball rug showing interaction with the capacitive areas.

The ball rug was connected to a laptop for a demonstration at Mental Health Awareness Week in Nottingham. The provisional computer setup showed that the various capacitive zones could be 
used to activate different symbols on screen. With wireless capability the rug is able to open different, pre-programmed uniform resource locators (URLS) on a tablet, phone or computer, or to connect to another textile interface with output modalities, such as the LEDs featured earlier in this article. This function was designed with the potential to be part of ongoing therapeutic discussions with Mind staff and could be tailored to access favourite songs, images, contacts or other preferred internet or computer content; it could also be used to communicate emotional experience in more ambiguous, poetic and even beautiful ways (Wallace and Press 2004), or become a controller for immersive experiences.

\section{Cushions}

Two cushions were also developed to respond to the need for large-scale textile objects (Figures 6 and 7). Common interior products, such as cushions, have often been the focus of electronic developments, as a familiar and tactile object in which to demonstrate the potential of the poetic possibilities of electronic textiles (Worbin 2010). For our project, the cushions were designed to illustrate different electronic textiles technical possibilities: a digital input and an analogue input, and to act as wireless output devices in communication with other objects developed in the frame of the project.

\section{Triangle LED cushion}

The first cushion is made of felt with triangle transparent insertions to illustrate digital input. Based on two parallel circuits, the cushion uses a Photon board allowing wireless communication with the other objects or with the data generated by the computer science department. To make a clear demarcation for the two circuits, the team used visual indicators such as the direction of the triangles (vertical and horizontal) and different colours (blue and white) for the LEDs used. In collaboration with the computer science researcher, the textile designers developed different patterns of activation (same time blinking, alternative blinking, different rhythm of blinking). Scenarios for use can now be developed by the participants themselves in response to direct experience with the cushions and LEDs as situated poetic information. 


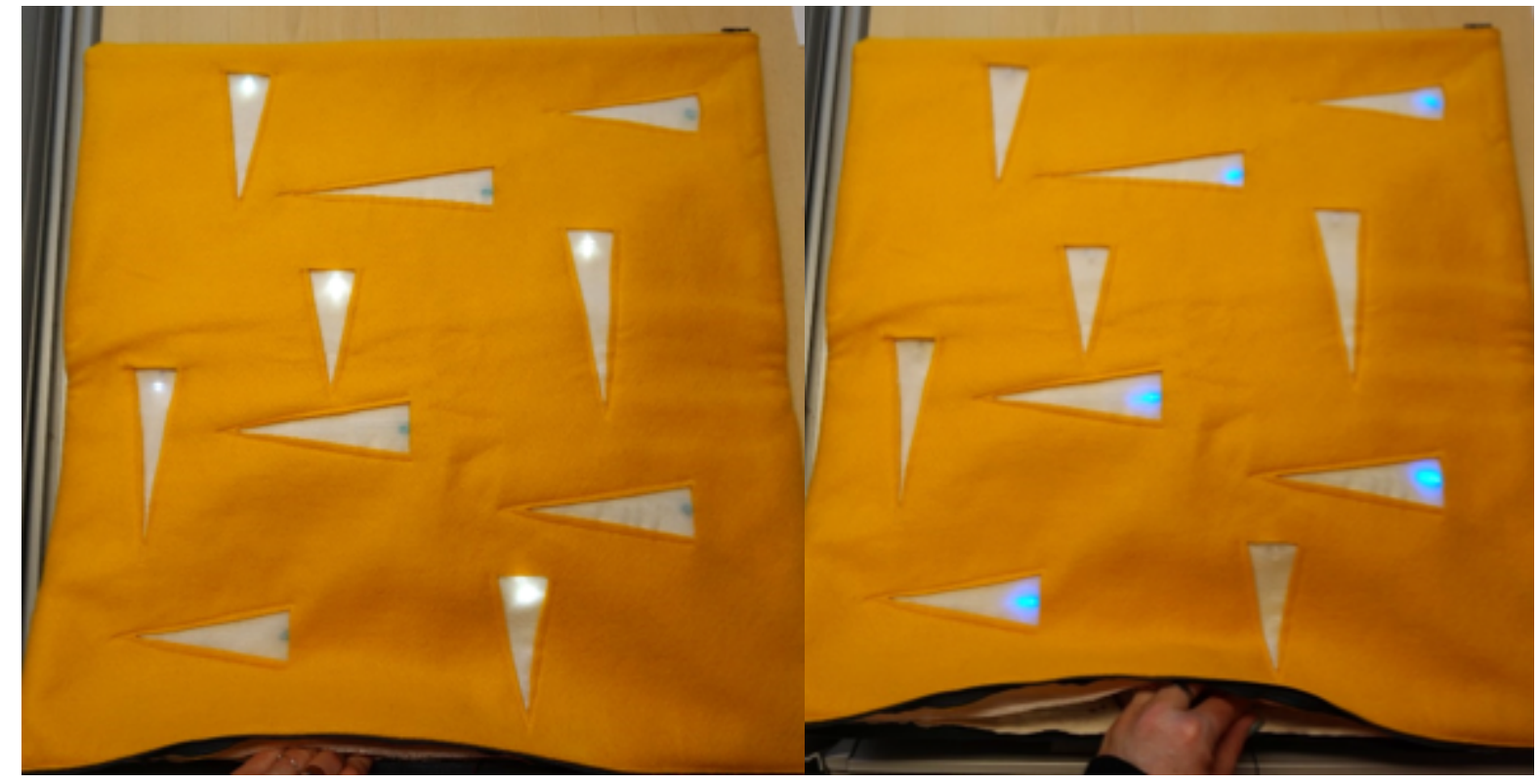

Figure 6. LED cushion showing two configurations of light output.

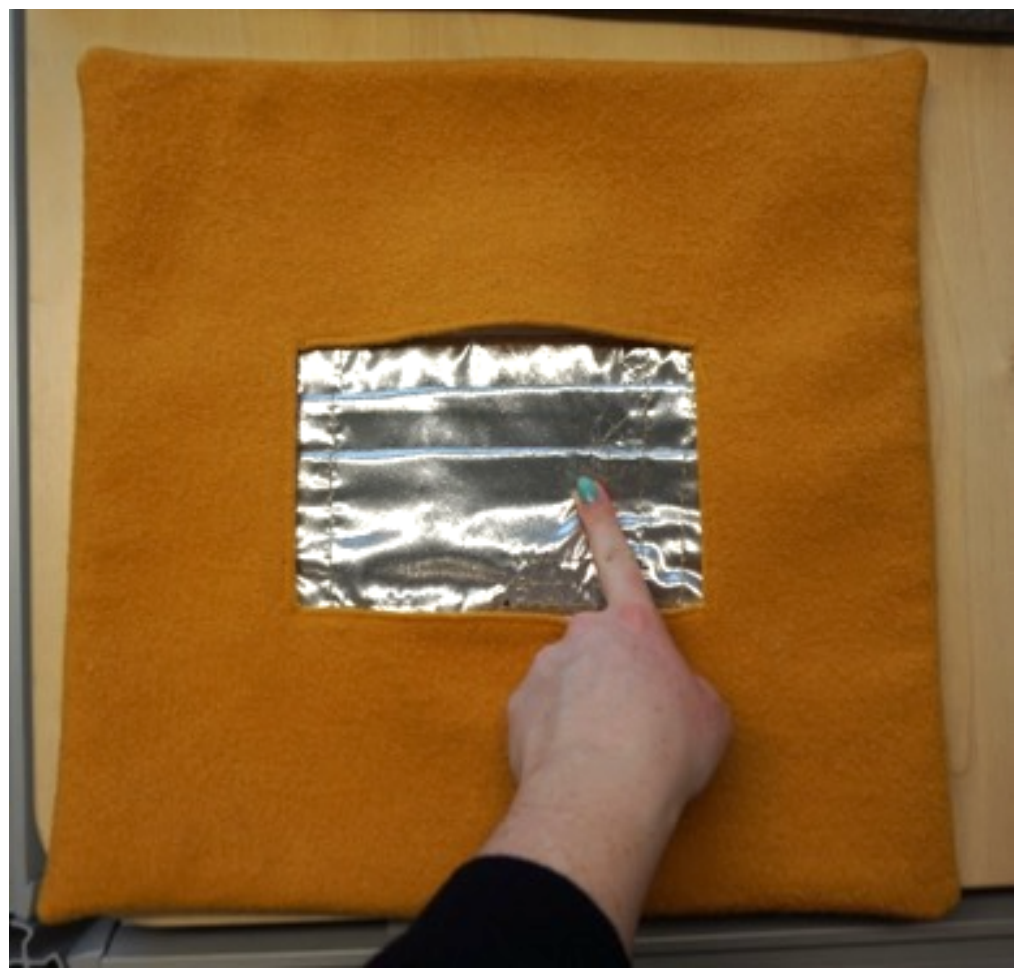

Figure 7. Cushion with LEDs and push buttons in silver insert.

The second cushion mixed different textile materials (felt and silvered fabric) to illustrate an analogue input. If the felted part of the cushion was neutral from an electronic point of view, the silvered part incorporated three push button sensors and three parallel LED circuits. Semitransparent, the silvered fabric allowed the light of the LEDs to glow through its surface. When one of the push buttons was pressed, the related LED circuits would flash. 


\section{Design practice - losses and gains through co-design and collaboration}

\section{Changes in design process}

The processes for the designers during the designer-led object development in loSofT featured some key differences from typical design tasks and familiar design processes. In accordance with the experiential PCA, the design brief was not defined by user 'need' or deficit, and was thus experienced by the designers as extremely open, and as having very few design constraints. The constraints given were related to scale, such as 'hand-held' or 'room scale'; 'input' or 'output' textile; or that it might contain particular components such as an accelerometer or a photon board. This open brief meant that it was often difficult to find a starting point for the objects' development, so the textile designers looked for inspirations from their experiences within the participatory workshops. One such experience was the decision to keep the interfaces easy to use. Many of the participants had expressed unfamiliarity with electronics or software so this gave an opportunity for the textiles to provide simple interfaces for more complicated 'behind the scenes' technology. In this case, it was important that the buttons or other actuators could be easily distinguished from the rest of the object and that the interfaces were as intuitive as possible. Since the purposes of the electronic textiles were not pre-determined, it was left to the designers to develop their own outcomes based on feedback from the workshops at Mind. Because of this openness, many major decisions relating to the preferred technology for networking could be led by the designers, in collaboration with a computer scientist.

\section{Aesthetic control and credibility}

The participant-led textile objects created in the Mind workshops during phase 1 presented specific challenges to experienced design practitioners. As the team were assisting and not leading the development of the textiles, it was inappropriate to be involved in decision-making about shapes, colour or even neatness of the objects. Our roles were to help participants to make their own design decisions and assist when invited. As such, it felt difficult for the practitioners to 'let go' of the fine details and resist the urge to 'tidy up' or 'correct' any of the participants' making. The only instance in which critical feedback might be given during the participant workshops was in order to make sure that any electrical circuits would function.

\section{Positive experiences in collaborative relationships}


The collaborative approach provided certain meaningful and rewarding engagements with individual Mind participants. The participants and facilitators in the workshops often developed oneto-one relationships. For example, one facilitator-participant pair developed their own unique sewing technique where both people were involved in the production of each stitch.

The collaborations within the research teams also provided opportunities for worthwhile gains for the researchers. The chance to work collaboratively between textile designers, computer scientists and person-centred therapists provided opportunities to reframe textile practice as a hybrid practice. Each disciplinary consideration needed to be represented and the self-negotiated briefs needed to take into account the requirements of users (who are variously familiar with different forms of technology, including textiles) and include complex technological components.

\section{Person-centred approach}

The PCA guided the structure and content of the Mind workshops (Glazzard et al. 2015). It also framed the design and potential use of the electronic textile objects in that the design approach tried to be experiential and non-directive (Levitt 2005). The research took a non-medicalized approach to participants' mental health and so the team did not seek to create objects in reaction to particular symptoms or diagnoses. The team were not working to diagnostic criteria or addressing the idea of a mental health deficit, but using a more holistic picture of mental health on the understanding that everyone has mental health (Mental Health Taskforce Strategy 2016).

\section{Difficulties with the smart textiles}

The design team came across several challenges to organising collaborative making sessions together. Each team member had individual commitments outside of the project which often dictated when and where making sessions would take place. Also, for those involved in the making sessions, each came from a different location within the University, with one member making fortnightly travel arrangements from abroad. The computer scientist in the team also found problems accessing the necessary equipment and technology from different locations.

A particular gain for the project team members was that in spite of limited equipment, the design work often took place in a studio-like location where conversations could take place freely. This became crucial towards building a meaningful and rewarding relationship that would impact on the design work. A constant challenge was the amount of time, iterations and attempts required to make functioning networked, textile objects. Each member needed to be efficient with time spent 
on developing the textile objects and set regular achievable goals. Due to the distinctive separate nature of the textiles and electronic materials, the design team realised that they had to be patient and methodical in their approach as a team and to each other in order to tackle the challenges encountered in the making.

\section{Technological problems}

The main problem with integrating the technology was the issue of powering the photon board. Available conductive threads allowed enough current flow to power LEDs from batteries and to power components running from the board, but they did not allow enough current flow between the battery and the board, due to the high power requirements needed to run the WIFI. The problem with the current flow caused frequent problems with the early devices using Photon boards, but the issue was not identified until later on, causing significant loss of development time.

After conducting some tests on the conductive threads available to us, it was discovered that the minimum amount of thread needed would be four to six ends of the thicker three or four ply threads (Figure 8). Due to the bulk caused by having so many ends of each yarn, it was problematic when sewing the photon board to the textiles. Possible solutions to this issue were to 'break out' the board so that the pins would be spread further apart on the board, to avoid short circuiting through fibre contact, or to use copper wiring to connect the battery to the photon board. Ultimately, due to time constraints, copper wire was used to connect the photon board to the battery, but attempted to be sensitive to textile considerations by using soft, flexible copper wire and twisting the outer ends into loops which could be stitched down. As a response to the issues described the team have begun to develop a soft circuitry kit to facilitate the development of large-scale objects (Figure 9). Using these textile-based boards may fill the gap between the already existing boards (Lilypad and Photon) and the input and output elements of electronic textile objects, as they can be easily attached and detached by using the press studs. 


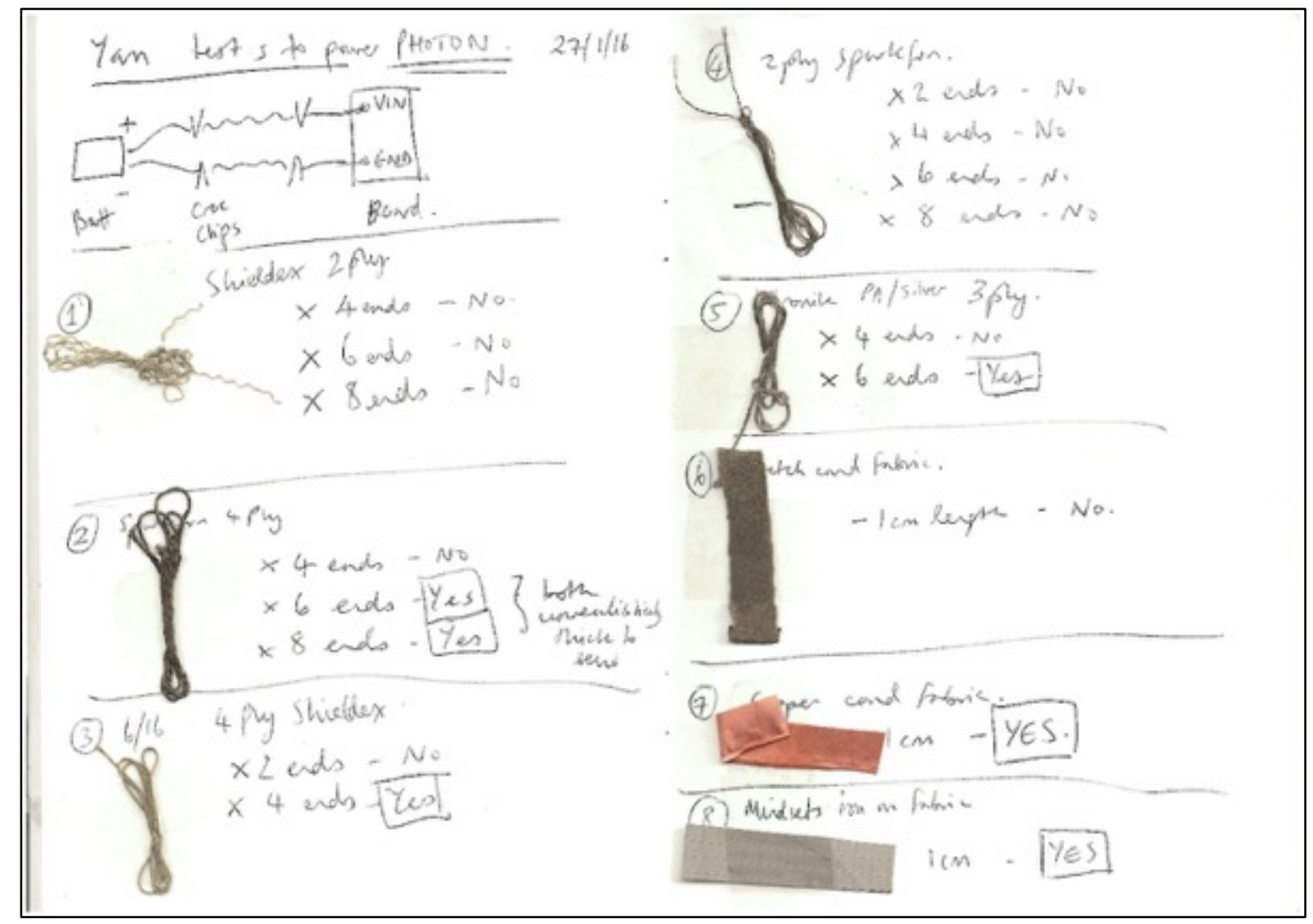

Figure 8. Image showing results of testing on conductive thread and fabric when used to power Photon board.
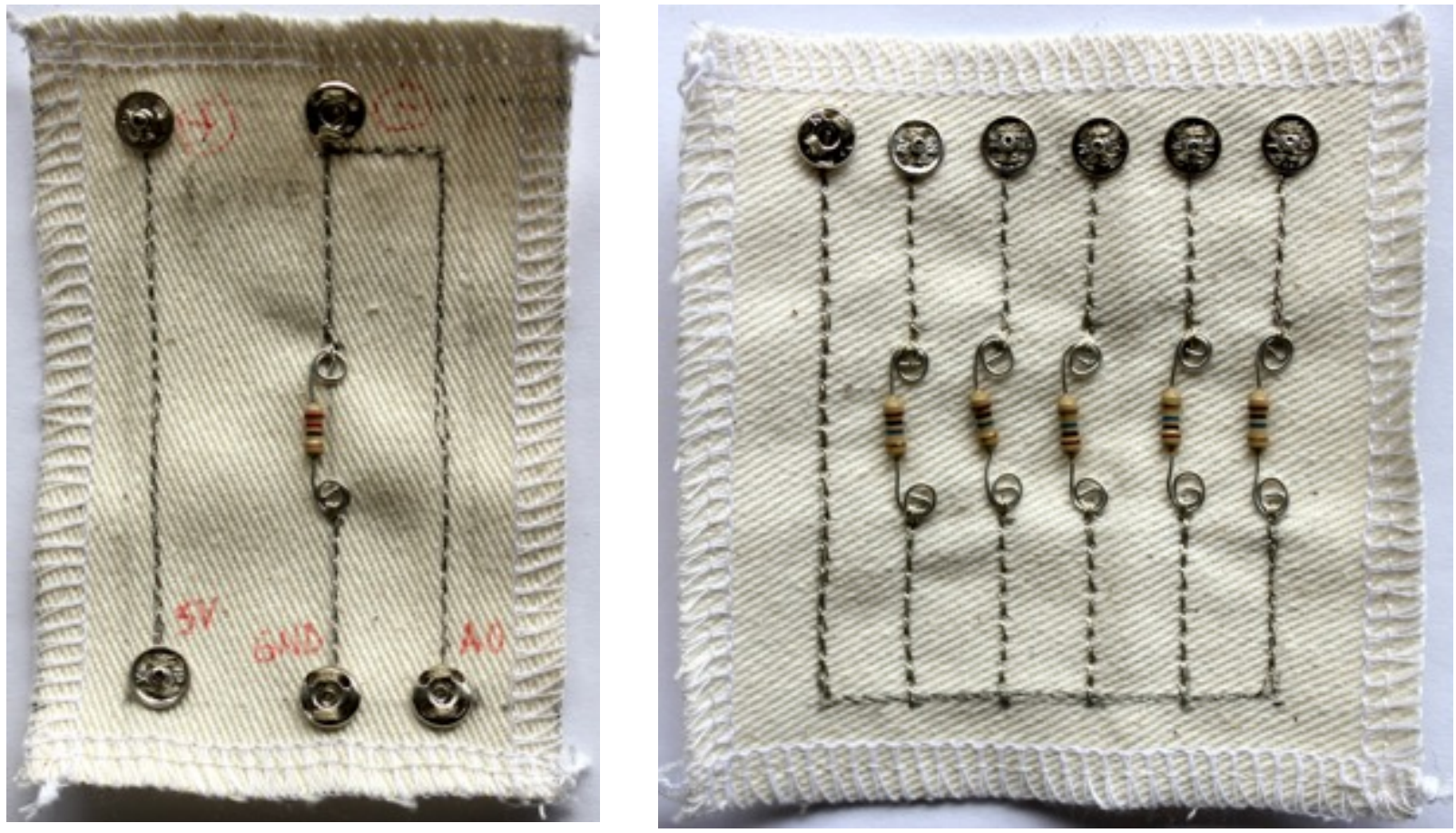
Figure 9. Examples of soft circuitry for a) a flex sensor and b) five capacitive sensors.

\section{Development of the toolkit}

One major outcome of the project, a toolkit, was produced to share the content of the Mind workshops with future service users (An Internet of Soft Things 2016b). 50 kits made available to Mind, were produced, each containing a booklet with educational resources, therapeutic feedback sheets based on the Recovery Star (MacKeith et al. 2013), and the equipment necessary to make the electronic textiles from the six-week Mind workshops. The toolkit has been designed to be used in group settings with assistance from a workshop leader(s) and volunteers. It has also been designed to accompany an 'in-house' kit at Mind, containing shared tools and equipment such as scissors, needles, etc.

The toolkit was designed to offer as much clarity as possible to each task. The educational material in the form of handouts and instructions included in the booklet were originally designed for use in the workshops and then frequently revised and edited based on feedback from participants in the workshops and on facilitators' observations. Where possible diagrammatic and photographic versions of visual information were used to help visualise tasks to different participants who have varying needs or preferences. Similarly, the electronic components were included in both literal and diagrammatic representations, to encourage the idea that the components may change, but the principles and methods can be transferred to use with other components. The Mind participants seemed to respond best to information that was broken into small chunks and that focused on one activity at a time, so the toolkit aims to reflect these requirements, particularly in the 'how to' guides written for each of the five activities (Figure 10).

Language used to describe the practical activities was accessible to a wide audience with varying education levels and who are assumed to be non-specialists in textiles or electronics. With these considerations in mind, the booklet contains introductory instructions to sewing, including how to thread a needle and tie a knot, and also basic electronic information such as a glossary of terms and explanations of series and parallel circuits. Aesthetically the toolkit is designed to be an engaging resource rather than an academic document or National Health Service publication. Bright colours (taken from the project logo) and a dashed line/stitching motif on plain text pages were used to add playful elements. The toolkit booklet is open access and can be freely downloaded from http://aninternetofsoftthings.com/toolkit. Because of its language and appearance, it is hoped that 
the toolkit booklet will be shared with other interested parties and be used to spread electronic textile knowledge to wider, non-specialised audiences.

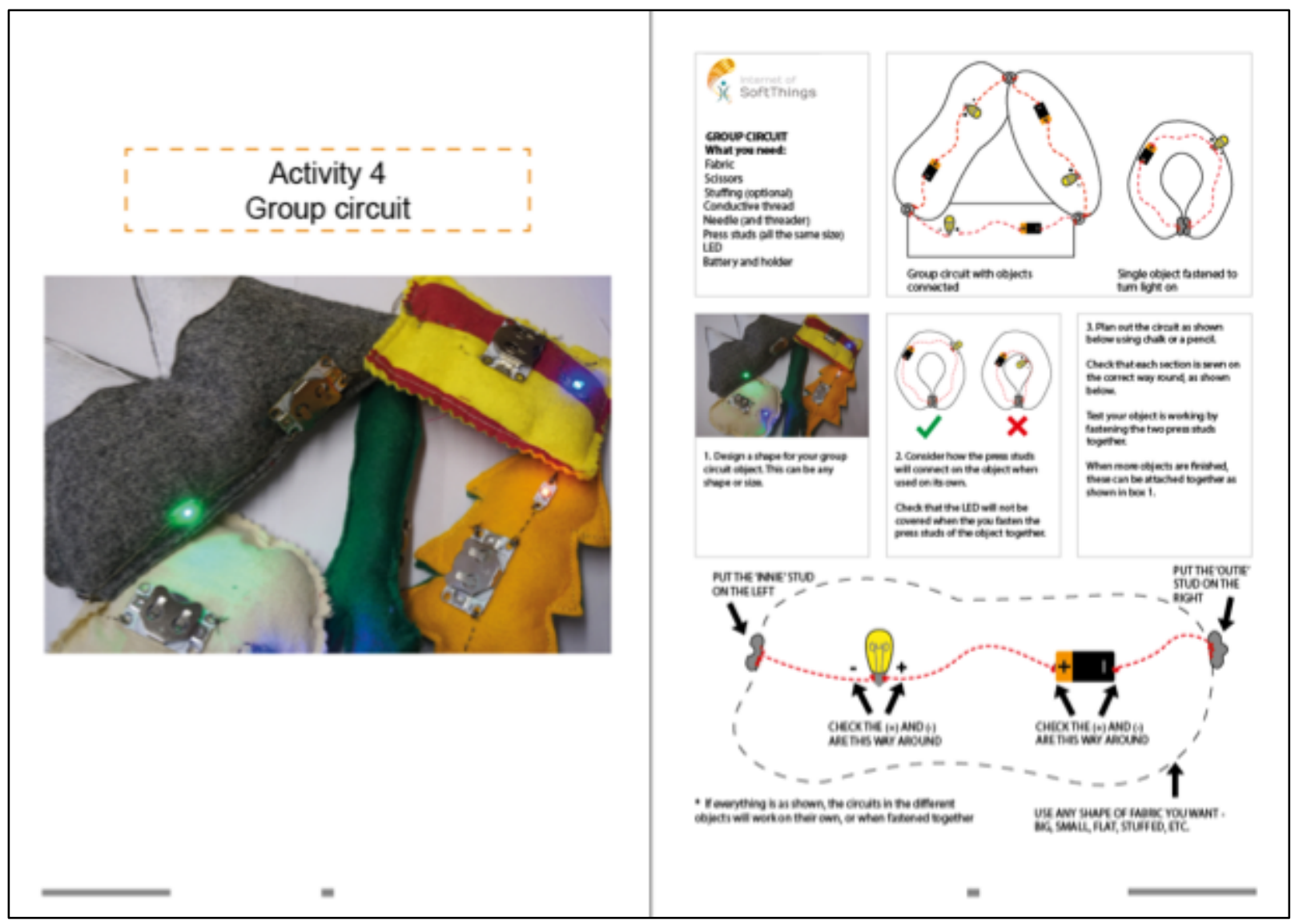

Figure 10. Example spread from the toolkit booklet showing a photograph of example outcomes and a 'how to' sheet for the activity.

\section{Concluding Remarks}

This paper has shown how a multidisciplinary team came together, to develop a new methodology that utilises co-design and craft making with electronic textiles within a person-centred framework. Reflection on the workshops and the making processes shows how the team used reflexive tools to build and respond to co-researchers' feedback, which enabled changes to be made to timings and planning. Thus, the team were able to respond dynamically to support the therapeutic growth of the individual within the context of the workshops themselves.

The paper also discussed challenges thrown up by the project for the textile designers in the form of a-typical design scenarios. There were challenges in the openness of the brief as well as the lack of aesthetic control involved in the making process. To ensure the authenticity and credibility of the making experience for the co-researchers it was paramount that any 'expert' views on what the object should do, how it should look, or on improving the appearance should be limited to a support 
role and not directing or doing. However, these challenges also revealed new directions and meanings for textile practice, which were experienced as both fulfilling and valuable.

There were also a number of technical design challenges in relation to the textile objects, which the textile design research team experienced as frustrating, such as protracted timelines and the numerous iterations of an object that were required for ultimate success. Some of these frustrations illustrate that the textile craft maker or designer often struggles in collaboration with others during the making process. However, the researchers also gained from collaboration with such a diverse team and were enriched by dialogue and new insights into other academic disciplines. This enabled a re-framing of textile design practice, from an individual pursuit with specified market-driven ambitions, into a more hybrid activity and a multi-layered experience with individual users at its centre.

The research project has delivered outcomes, which have demonstrated that a diverse team of academics and practitioners can provide alternative approaches to design with and for mental health, through bringing the voices of people with lived experience into the conversation about how we as a society wish to engage with electronic textiles as part of an Internet of Things.

\section{References}

An Internet of Soft Things 2016a. An Internet of Soft Things [online]. Available at: http://aninternetofsoftthings.com/ [Accessed 9 March 2016].

An Internet of Soft Things 2016b. Electronic Textile Workshop Toolkit: Workshop Guide. Available at: http://aninternetofsoftthings.com/toolkit/ [Accessed 4 October 2016].

Briggs-Goode, A., Glazzard, M., Walker, S. 2015. An Internet of Soft Things. In: Futurescan 3: Intersecting Identities, Glasgow School of Art, 11-12 November 2015. Glasgow: Glasgow School of Art.

Brown, D., McHugh, D., Standen, P., Evett, L., Shopland, N. and Battersby, S. 2011. “Designing location based learning experiences for people with intellectual disabilities and additional sensory impairments." Computers and Education, 56(1), 11-20.

Burt, E., and Atkinson, J. 2012. "The Relationship between Quilting and Wellbeing." The Journal of Public Health, 34(1): 54-59. 
Embleton-Tudor. L., Keemar K., Tudor, K., Valentine, J. and Worrall, M. 2004. The Person-Centred Approach: A Contemporary Introduction. Basingstoke: Palgrave Macmillan.

Fritzing 2016. Fritzing: Electronics Made Easy [online], Fritzing, Available at: http://fritzing.org/home/ [Accessed 2 March 2016].

Glazzard, M., Kettley, R., Kettley, S., Walker, S., Bates, M. and Lucas, R. 2015. “Facilitating a 'nonjudgmental' skills-based co-design environment." In: Proceedings of the Third European Conference on Design4Health 2015, Sheffield Hallam University, 13-16 July: 1-12.

Gray, C. and Malins, J. 2004. Visualizing research: a guide to the research process in art and design. Aldershot: Ashgate.

Innovate UK Network. 2013. A roadmap for Interdisciplinary Research in the loT, March 2013. Innovate UK Network Internet of Things Special Interest Group (IoT SIG). Available at: https://connect.innovateuk.org/web/internet-of-things [Accessed 4 October 2016].

Jaatinen, P. 2015. Rethinking Visual Art Practice in Relation to Well-Being. A Conceptual Analysis. PhD Dissertation, University of Jyväskylä

Kettley, S., Kettley, R. and Lucas, R. (forthcoming). “From Human-Centred to Person-Centred Design." In I. Kuksa and T. Fisher, T. (Eds). Design and Personalization. Abingdon: Gower/Routledge.

Levitt, B. 2005. Embracing Nondirectivity: Reassessing Person-centred Theory and Practice in the $21^{\text {st }}$ Century. Ross-on-wye: PCCS Books Ltd.

Mackeith, J. et al., 2013. Mental health recovery star: user guide. 3rd edition. London: Mental Health Providers Forum.

Mental Health Taskforce Strategy (2016). The Five Year Forward View for Mental Health. NHS England. Available at: https://www.england.nhs.uk/wp-content/uploads/2016/02/Mental-HealthTaskforce-FYFV-final.pdf. [Accessed 4 October 2016]. 
Particle, 2016. Prototyping Tools for the Internet of Things [online]. Particle. Available at: https://www.particle.io/prototype [Accessed 2 March 2016].

Rogers, N. 1993. Creative Connection: Expressive Arts as Healing. Palo Alto: Science and Behaviour Books.

Rogers, C. 1957. "The Necessary and Sufficient Conditions of Therapeutic Personality Change." Journal of Consulting Psychology. 21 (2), 95-103.

Rogers, C. 1961. On Becoming a Person: A Therapist's View of Psychotherapy. London: Constable.

Tyrer, P. and Steinberg, D. 2013. Models for Mental Disorder. $5^{\text {th }}$ edition. Chichester: Wiley.

Blackwell Wallace, J., and Press, M. 2004. "All this useless beauty: finding beauty through craft in digital technology." PixelRaiders2. Sheffield: Sheffield Hallam University.

Wallis, M. and Jones, I. 2013. "Acts of Poiesis: salamanda tandem." In P. Duggan and V. I. Ukaegbu (Eds.). Reverberations across Small-Scale British Theatre: Politics, Aesthetics and Forms, pp. 195-216. Bristol: Intellect.

Worbin, L. 2010. Designing Dynamic Textile Patterns. University of Boras: Studies in Artistic Research. Available at: https://www.diva-portal.org/smash/get/diva2:876942/FULLTEXT01.pdf. [Accessed 4 October 2016].

Yair, K., 2011. Craft and Wellbeing, Research Paper for the Crafts Council UK, March 2011. Available at: http://www.craftscouncil.org.uk/content/files/craft_and_wellbeing.pdf [Accessed 4 October 2016].

MHPF: National Alliance of Voluntary Sector Mental Health Providers. 2016. The Recovery Star and Resources. Available at: http://www.mhpf.org.uk/programmes/mental-health-and-recovery/therecovery-star. [Accessed 4 October 2016].

\section{List of Figures}

Figure 1. Fritzing diagram showing schematic for handheld electronic textile object. 
Figure 2. Images of the outcomes of the five making activities with the Mind participant group.

Figure 3. Images of one of the hand-held objects using an accelerometer, on/off switch, push button and a three colour LEDs Lilypad board with a Photon board for wireless communication. Preparatory circuit sketch and intermediary object.

Figure 4. Capacitive ball rug in development showing the 5 panels pieces together with the appliqued conductive fabric.

Figure 5. Capacitive ball rug showing interaction with the capacitive areas.

Figure 6. LED cushion showing two configurations of light output.

Figure 7. Cushion with LEDs and push buttons in silver insert.

Figure 8. Image showing results of testing on conductive thread and fabric when used to power Photon board.

Figure 9. Examples of soft circuitry for a) a flex sensor and b) five capacitive sensors.

Figure 10. Example spread from the toolkit booklet showing a photograph of example outcomes and a 'how to' sheet for the activity. 